\section{Potential of Honeybee Brood Pheromone to Enhance Foraging and Yield in Hybrid Carrot Seed}

\author{
Ramesh R. Sagili ${ }^{1,4}$, Carolyn R. Breece ${ }^{1}$, Rhonda Simmons ${ }^{2}$, and \\ John H. Borden ${ }^{3}$
}

AdDitional INDEX wORDs. Apis mellifera, pollination, flower visitation, pollen forager, crop yield

Summary. Honeybee (Apis mellifera) brood pheromone is a blend of 10 fatty acid esters that stimulates worker pollen foraging, protein biosynthesis in the brood foodproducing glands of nurse bees and queen oviposition. In separate experiments conducted in central Oregon, we tested the hypotheses that treatment of honeybee colonies with brood pheromone would stimulate increased bee foraging in hybrid carrot (Daucus carota) seed fields, and that in turn would result in increased seed yield. For both experiments, in each replicate, all honeybee colonies placed at one field were treated with brood pheromone, and those in a control field were not treated with brood pheromone. A total of 123,720 bee visits to flowers was recorded. For both sexes of flower, there were significantly more bee visits in fields in which colonies were treated with brood pheromone than in control fields $(P<0.05)$. There was also a significant preference for male flowers over female flowers $(P<0.05)$ by bees in the fields where colonies received brood pheromone when compared with control fields. Mean yields in fields pollinated by colonies treated with brood pheromone and those that were not treated with brood pheromone were 325.2 and $280.8 \mathrm{~kg} \cdot \mathrm{ha}^{-1}$, respectively. Mean percentage yield was significantly higher in fields where honeybee colonies received brood pheromone when compared with control fields that had colonies without brood pheromone $(P<0.01)$. Our results suggest that brood pheromone has the potential to increase honeybee foraging and seed yield in hybrid carrot seed crop.

$\mathrm{T}$ he honeybee, brood pheromone is a blend of 10 fatty acid esters (methyl and ethyl linoleate, linolenate, oleate, palmitate, and stearate) produced in the larval salivary glands (LeConte et al., 1990, 2006). Brood pheromone has been shown to increase protein content in the brood food-producing glands of nurse bees, thus increasing the quality of the diet fed to larvae and the queen (Mohammedi et al., 1996; Pankiw et al., 2004; Peters et al., 2010). It also stimulates queen egg laying rate (Sagili and Pankiw, 2009).

Honeybee adult workers show plasticity in age-based and hormonally regulated division of labor by adjusting

We thank the Agricultural Research Foundation at Oregon State University, Central Oregon Seeds Inc., Jefferson Seed Growers Association, Oregon State Beekeepers Association and SAKATA seeds for funding, Cristina Machial for graphics, and Contech Enterprises Inc. for donating SuperBoost.

${ }^{1}$ Department of Horticulture, OR State University, 4017 ALS Bldg., Corvallis, OR 97331

${ }^{2}$ Central Oregon Agricultural Research Center, 850 Dogwood Lane, Madras, OR 97741-8988

${ }^{3}$ Contech Enterprises Inc., Delta, BC, V4GIE9, Canada ${ }^{4}$ Corresponding author. E-mail: ramesh.sagili@ oregonstate.edu. their behavioral development pattern in response to shifts in colony conditions (Huang and Robinson, 1992). When synthetic brood pheromone was dispensed by offering minute amounts on a glass plate suspended between the combs of a hive, it had a remarkable impact on foraging by worker bees, including: increased ratio of pollen to nonpollen foragers (Pankiw and Page, 2001 ); more pollen foragers by up to 150\% (Pankiw, 2004; Pankiw and Page, 2001; Pankiw and Rubink, 2002); more pollen forager trips per unit time (Pankiw, 2007); and greater weight of pollen returned to the hive (Pankiw, 2004; Pankiw et al., 2004).

In seed crops, adequate pollination is the key for high seed quality and yield. Many hybrid seed crops are not very attractive to honeybees and they may be easily lured to alternative flowering plants that are more attractive (Delaplane and Mayer 2000). In spite of introduction of high number of honeybees, significantly lower number of bees was found foraging on hybrid carrot seed crop (Howlett, 2012). Improved production practices and new varieties may increase the yield of seed crops (Rao and Stephen, 2009), but there is a dearth of studies on managing pollinators as a potential method of improving yield.

Several tactics have been employed over the years to enhance pollination efficiency of bees, predominantly in crops that are not very attractive to bees because they might either produce low quantities and quality of nectar and pollen or environmental conditions are suboptimal during their bloom period. Bee attractants ranging from sugar syrup to bee pheromones such as Nasanov and queen mandibular gland pheromone have been tested to enhance bee visitation and crop yields with meager success (Delaplane and Mayer, 2000) or no success (Ellis and Delaplane, 2009; Mayer et al., 1989; Roper et al., 1990; Schultheis et al., 1994). Bee visitation, seed yield, and germination percent could be increased by pheromone-based bee attractants in niger [Guizotia abyssinica (Sivaram et al., 2013)]. Using queen mandibular pheromone (QMP) sprays, yield was increased in cranberry [Vaccinium oxycoccos (Currie et al., 1992a)], blueberry [Vaccinium corymbosum (Currie et al., 1992a)], and pear [Pyrus communis (Currie et al., 1992b)], but not apple [Malus $\times$ domestica (Currie et al., 1992b)].

Central Oregon accounts for $\approx 85 \%$ of hybrid carrot seed crop grown in the United States (Hart and Butler, 2004). This region offers warm day temperatures and cooler nights that are ideal for hybrid carrot seed production. Hybrid carrot seed production is based on the seed-to-seed method or the root-to-seed method.

\begin{tabular}{llll}
\hline $\begin{array}{l}\text { Units } \\
\text { To convert U.S. to } \\
\text { SI, multiply by }\end{array}$ & U.S. unit & SI unit & $\begin{array}{l}\text { To convert SI to } \\
\text { U.S., multiply by }\end{array}$ \\
\hline 0.4047 & acre $(\mathrm{s})$ & $\mathrm{ha}$ & 2.4711 \\
1.1209 & $\mathrm{lb} / \mathrm{acre}$ & $\mathrm{kg} \cdot \mathrm{ha}^{-1}$ & 0.8922 \\
1.6093 & $\mathrm{mile}(\mathrm{s})$ & $\mathrm{km}$ & 0.6214 \\
28,350 & $\mathrm{oz}$ & $\mathrm{mg}$ & $3.5274 \times 10^{-5}$ \\
0.9144 & yard$(\mathrm{s})$ & $\mathrm{m}$ & 1.0936
\end{tabular}


The seed-to-seed method is most common in central Oregon where parent lines are planted in August and the crop is harvested the next year during September. An isolation distance of 1 mile is recommended to avoid crosspollination with other hybrid carrot seed varieties and wild carrot if present in the production. In August, parent lines are planted in rows on 30-inch centers. Four rows of female plants are alternated with two rows of male plants with a blank row separating male and female rows. There is not much known regarding volume and concentration of nectar or amounts of pollen produced by these hybrid carrot varieties grown in central Oregon. Honeybees are extremely important pollinators for carrot seed crop in this region, and the fields on average are typically provided with three honeybee colonies per acre for pollination.

SuperBoost [Contech Enterprises, Delta, BC, Canada (Fig. 1)], a commercial product based on the honeybee brood pheromone, was used in this study. It comprises a small pheromone-permeable plastic pouch containing $180 \mathrm{mg}$ of a synthetic blend that precisely mimics the natural pheromone composition (Pankiw et al., 2010); the pouch is suspended in a rigid plastic holder between the frames at the level of the brood comb (Lait et al., 2012). Tertiary-butylhydroquinone, a food-grade antioxidant, is added as $0.05 \%$ of the total composition to stabilize the methyl and ethyl esters of linolenic, linoleic, and oleic acid.

When tested experimentally, synthetic brood pheromone has been shown to increase the ratio of pollen to nonpollen foragers (Pankiw et al., 2011), stimulate workers to bring heavier pollen loads back to the hive (Pankiw et al., 2011), enhance the vigor of colonies during spring buildup (Moeri et al., 2011) and fall feeding (Sagili and Breece, 2012), improve overwintering survival (Lait et al., 2012), and increase the amount of honey harvested (Borden et al., 2013; Foster et al., 2011; Lait et al., 2012). One synthetic brood pheromone device lasts for over 5 weeks (Pankiw et al., 2011).

Some field studies have shown brood pheromone to increase foraging activity of honeybees, but to our knowledge, there is a dearth of studies that have examined if this increased foraging activity actually leads to increase in crop yield. The only study that exists on this subject investigated the effect of synthetic brood pheromone on watermelon (Citrullus lanatus) yield in a greenhouse (Guerra Sanz and Roldán Serrano, 2008). Here, we examined whether brood pheromone treatment of colonies would increase foraging activity in honeybee colonies and thus increase yield of a horticultural crop (hybrid carrot seed). The specific objectives of this study were to 1 ) examine foraging activity (flower visitations in the fields, number of foragers entering colonies in 5-min intervals) of bees in fields where honeybee colonies received brood pheromone and fields with colonies that did not receive brood pheromone (controls) and 2) evaluate and compare crop yield between hybrid carrot seed fields in which colonies received brood pheromone treatment and control fields with colonies that did not receive brood pheromone.

\section{Materials and methods}

TEST FIELDS AND BROOD PHEROMONE TREATMENT. Twentyeight hybrid carrot seed fields ( 8 for flower visitation study and 20 for seed yield study) located within 10-mile radius around Madras, OR, served as experimental sites for this study from 2009 to 2012. These fields ranged from 13 to 50 acres in size and were managed by individual growers in a uniform manner, as guided by Central Oregon Seeds, Madras, OR. Crop management generally followed standard practice for central Oregon (Hart and Butler, 2004), and hence all the experimental fields had a similar regimen for fertilization, irrigation and pest/disease control. Further, all the experimental fields in this study had clay loam soils and uniform plant density. The Madras, OR, area where majority of the hybrid carrot seed production in Oregon is concentrated has a high desert arid climate with low rainfall and humidity, cool nights, and moderate summer temperature. Managed honeybee colonies are the predominant pollinators of carrot seed crop and the other native pollinators such as bumble bees are either rare or not observed in adequate numbers during carrot bloom. In August, parent lines were planted in rows on 30-inch centers. Four rows of female plants were alternated with two rows of male plants with a blank row separating male and female rows.
Honeybee colonies were placed around the perimeter of the hybrid carrot seed fields at an average density of three colonies per acre in July of the following year when carrot crop bloom was $\approx 5 \%$. Each honeybee colony was composed of two standard brood boxes with $\approx 50,000$ bees. Paired treatment and control fields were selected such that they were at least 3 miles apart from each other to avoid any overlap of bees foraging in these fields. For both experiments described below, isolated hybrid carrot seed fields with same varieties, irrigation type, and management were used to allocate treatments. These selected fields were randomly designated as brood pheromone treatments (brood pheromone device inserted into honeybee colonies) or controls (no brood pheromone in honeybee colonies). Brood pheromone treatment colonies received one synthetic brood pheromone device in the brood area, within 1 week after hive placement, whereas control colonies received a blank device without pheromone. All the colonies around the treatment field in each replicate (pair of fields) were treated with brood pheromone. Honeybee colonies remained in the fields for 5-6 weeks until the end of bloom. Seed from the fields was harvested in September of the second year.

FLOWER VISITATION EXPERIMENT. Flower visitation by honeybees was evaluated in eight carrot seed fields (three replicates in 2009 and one in 2010). Flower visitation by a bee constituted a bee alighting on a flower and staying on the flower for at least $5 \mathrm{~s}$. Isolated hybrid carrot seed fields with same varieties, irrigation type, and management were used to allocate treatments. These selected fields were randomly designated as brood pheromone treatments (brood pheromone device inserted into honeybee colonies) or controls (no brood pheromone in honeybee colonies). Brood pheromone treatment colonies received one synthetic brood pheromone device in the brood area, whereas control colonies received a blank device without pheromone. After initiation of the experiment, in each experimental field we counted the number of bees visiting both male and female flowers during a 5-min transect (Ellis and Delaplane, 2009). During each 5-min observation period, six people walked in straight rows at a similar pace counting bees on both male and female umbels using 
tally counters. A distance of 250 yards was covered on average during each 5-min transect. Bee visitation counts were documented three times per day (between 0900 and $1400 \mathrm{HR}$ ) and twice per week during the 5-week study period.

COLONY FORAGING BEHAVIOR. Thirty honeybee colonies in each experimental field (same eight experimental fields mentioned above in flower visitation experiment) were randomly selected to analyze foraging behavior. The number of pollen and nonpollen foragers entering the experimental colonies in a 5 -min period was recorded twice per day (between 0800 and $0900 \mathrm{HR}$ and between 1100 and $1200 \mathrm{HR}$ ) and three times during each week until the end of bloom.

Crop yield EXPERIMENT. This experiment was replicated 10 times (total of 20 carrot fields), with 2 replicates completed in 2010, 4 in 2011, and 4 in 2012. These experimental fields with same varieties, irrigation type, and management were randomly designated as brood pheromone treatments (brood pheromone inserted into honeybee colonies) or controls (no brood pheromone in honeybee colonies). Brood pheromone treatment colonies received one synthetic brood pheromone device in the brood area, whereas control colonies received a blank device without pheromone. Carrot seed after harvest from each of the treated and control fields was kept separate and was weighed after cleaning to obtain final seed yield.

Statistical anAlyses. Numbers of flower visits and weights of seed/ha were highly variable between replicates $(2.5 \times$ variation between lowest and highest replicates for flower visits and $10.2 \times$ for seed yield). Therefore, data were normalized by conversion to percentages within each replicate (e.g., in hectare was harvested from the brood pheromone field and $40.2 \%$ of the seed/ha was harvested from the control field). The means for all of the percentages (mean percentages) were compared between treated and control fields by two-tailed $t$ tests for visits to male or female flowers $(\mathrm{N}=$ eight fields), and (for male and female flowers separately) to flowers in the four fields pollinated by pheromone-treated colonies compared with flowers in the four fields pollinated by untreated control colonies. Similarly, the mean percentage of seed harvested from the 10 fields pollinated by pheromone-treated colonies was compared by a two-tailed $t$ test one replicate, $59.8 \%$ of the seed per

to the mean percentage of seed harvested from the 10 control fields pollinated by untreated colonies. Chi-square contingency table analysis was used to analyze the proportion of pollen to nonpollen foragers.

\section{Results}

Flower visitation. Overall, 123,720 bee visits to flowers were recorded in the eight fields sampled. For both sexes of flower, there were significantly more visits in fields pollinated by colonies treated with brood pheromone than in control fields (male flowers $t=2.9$, df $=6, P=0.02$; female flowers $t=2.47, \mathrm{df}=6, P=0.04$ ) (Table 1). There was also a significant

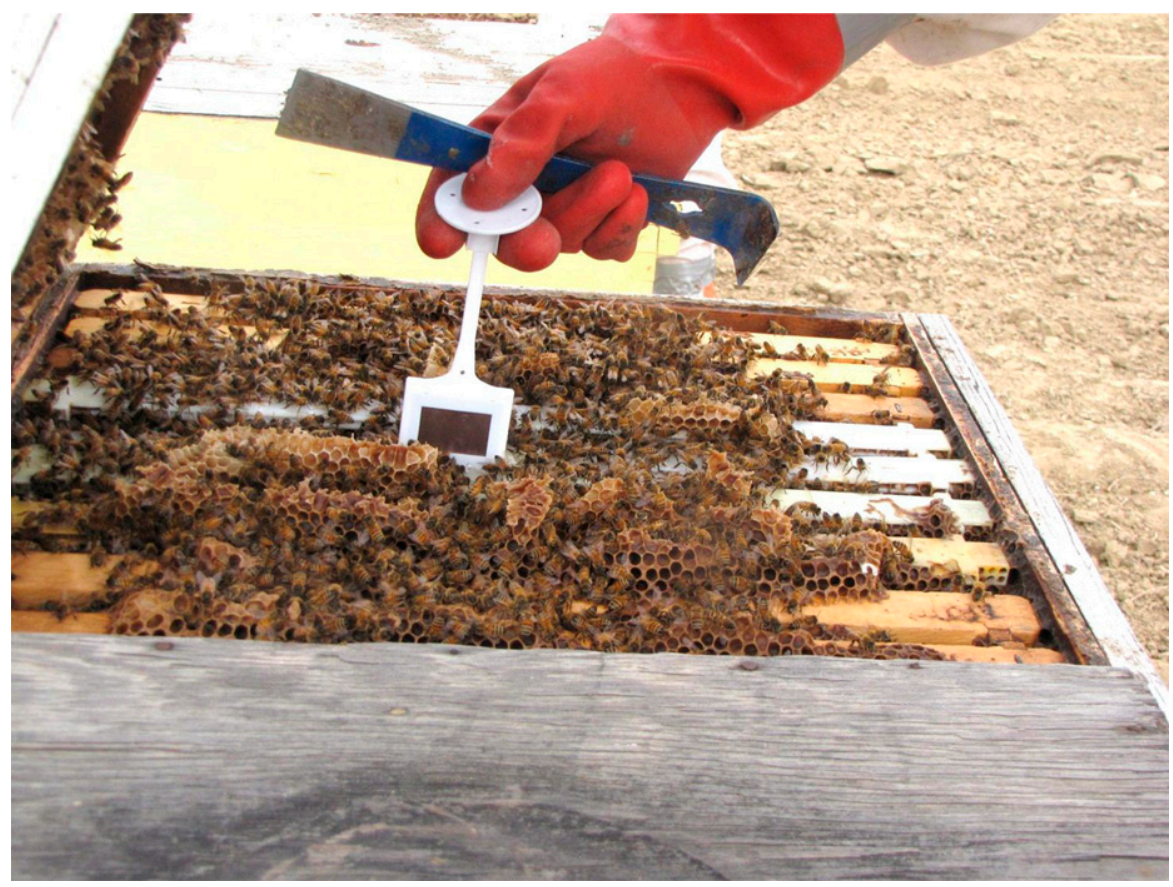

Fig. 1. Photograph of Brood pheromone (SuperBoost, Contech Enterprises, Delta, BC, Canada) being placed between the frames of a honeybee hive. Rectangular dark area surrounded by white plastic is plastic pouch containing $180 \mathrm{mg}(0.0063 \mathrm{oz}) \mathrm{of}$ synthetic brood pheromone.

Table 1. Comparison of honeybee visits to male and female carrot flowers in fields pollinated by colonies treated with brood pheromone or by untreated control colonies, and to male or female flowers (all fields combined). Mean percentages are calculated as the means of the percentage distributions of all visits within each replicate. $\mathrm{N}=4$ for each sex of flower and $\mathrm{N}=8$ for both sexes of flower.

\begin{tabular}{llcc}
\hline Sex of flower & \multicolumn{1}{c}{ Criterion evaluated } & $\begin{array}{c}\text { Honeybee visits } \\
\text { [mean } \pm \text { SE }(\mathbf{n o .})]\end{array}$ & $\begin{array}{c}\text { Honeybee visits } \\
\text { [mean } \pm \text { SE (\%)] }\end{array}$ \\
\hline Male & Flower visits in brood pheromone fields & $11,089 \pm 1,316$ & $59.2 \pm 4.5^{*}$ \\
& Flower visits in control fields & $7,630 \pm 1,012$ & $40.8 \pm 4.5$ \\
Female & Flower visits in brood pheromone fields & $6,968 \pm 971$ & $59.7 \pm 5.6^{*}$ \\
& Flower visits in control fields & $5,227 \pm 1,374$ & $40.3 \pm 5.6$ \\
Both sexes-combined & Visits to male flowers & $18,735 \pm 1,645$ & $61.6 \pm 3.5^{* *}$ \\
& Visits to female flowers & $12,195 \pm 2,300$ & $38.5 \pm 3.5$ \\
\hline
\end{tabular}

* Significant difference between paired mean percentages at $P \leq 0.05$ (two-tailed $t$ test).

** Significant difference between paired mean percentages at $P \leq 0.01$ (two-tailed $t$ test). 
preference for male flowers over female flowers $(t=4.7, \mathrm{df}=6, P=0.003)$ (Table 1).

Colony forager counts. The proportion of pollen foragers returning to the colonies in 5-min interval was significantly higher in colonies treated with brood pheromone $(2 \times$ 2 contingency table analysis $\chi^{2}=17.4$, $\mathrm{df}=1, P<0.001)$. Furthermore, the mean sum of total foragers entering colonies in a 5-min interval was significantly higher in brood pheromone treatment (analysis of variance, $\mathrm{F}_{1,238}=$ 156.2; $P<0.0001)$.

YIELD. The yield in fields pollinated by colonies treated with brood pheromone ranged from 81.3 to 782.5 $\mathrm{kg} \cdot \mathrm{ha}^{-1}$, while the yield in fields pollinated by untreated control colonies ranged from 74.4 to $813.4 \mathrm{~kg} \cdot \mathrm{ha}^{-1}$. Mean yields in fields in which colonies were treated with brood pheromone and not treated with brood pheromone were $( \pm$ SE) $325.2 \pm 65.0$ and $280.8 \pm$ $63.7 \mathrm{~kg} \cdot \mathrm{ha}^{-1}$, respectively. Mean percentages of total seed yield per replicate in fields where honeybee colonies received brood pheromone treatment and in control fields that did not receive brood pheromone were $53.7 \%$ and $46.3 \%$, respectively, and were significantly different $(t=3.5 \mathrm{l}, \mathrm{df}=18, P=$ 0.002 ) (Fig. 2).

When the percentage differences in yield between treated and control fields were plotted individually for each replicate, six of the 10 replicates showed a positive effect of brood pheromone treatment (Fig. 3). The higher yields in the brood pheromone treatment fields pertaining to these six replicates ranged from $8.5 \%$ to $64.5 \%$ when compared with corresponding control fields (Fig. 3). In one replicate, treated and control fields had equal yields, and in the three remaining replicates, the lower yields in treated fields than control fields ranged from $-1.4 \%$ to $-3.8 \%$. Overall, the mean difference in yield in favor of fields pollinated by colonies treated with brood pheromone was $+18.3 \% \pm 7.6 \%$.

\section{Discussion}

Flower visitation. While treatment of honeybee colonies with synthetic brood pheromone is known to stimulate foraging (Pankiw, 2004, 2007; Pankiw et al., 2004, 2011; Pankiw and Page, 2001; Pankiw and Rubink, 2002), all measurements to date have been on division of labor

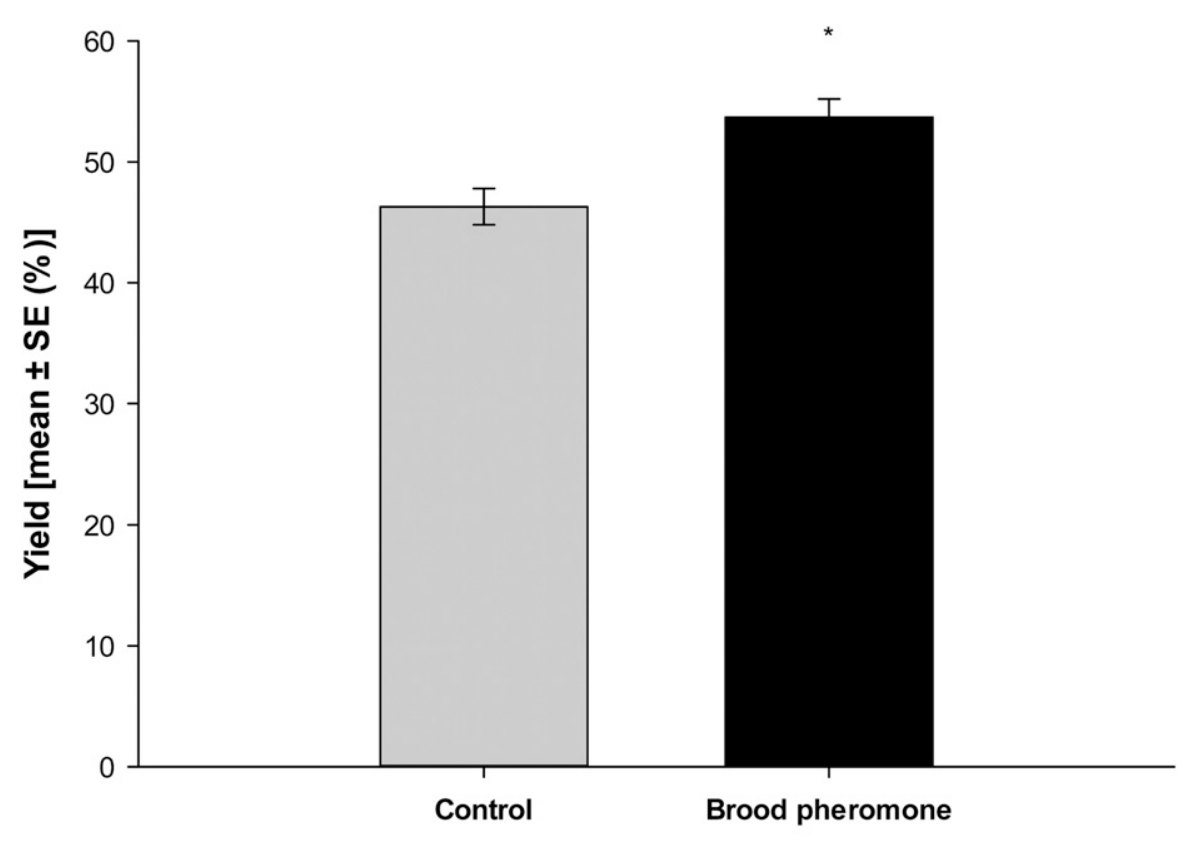

Treatments

Fig. 2. Graph showing mean percentage of total seed yield per replicate from 10 fields stocked with honeybee hives treated with brood pheromone and 10 fields stocked with hives that did not receive brood pheromone treatment. Asterisk indicates significant difference $(P \leq 0.01)(t$ test $)$.

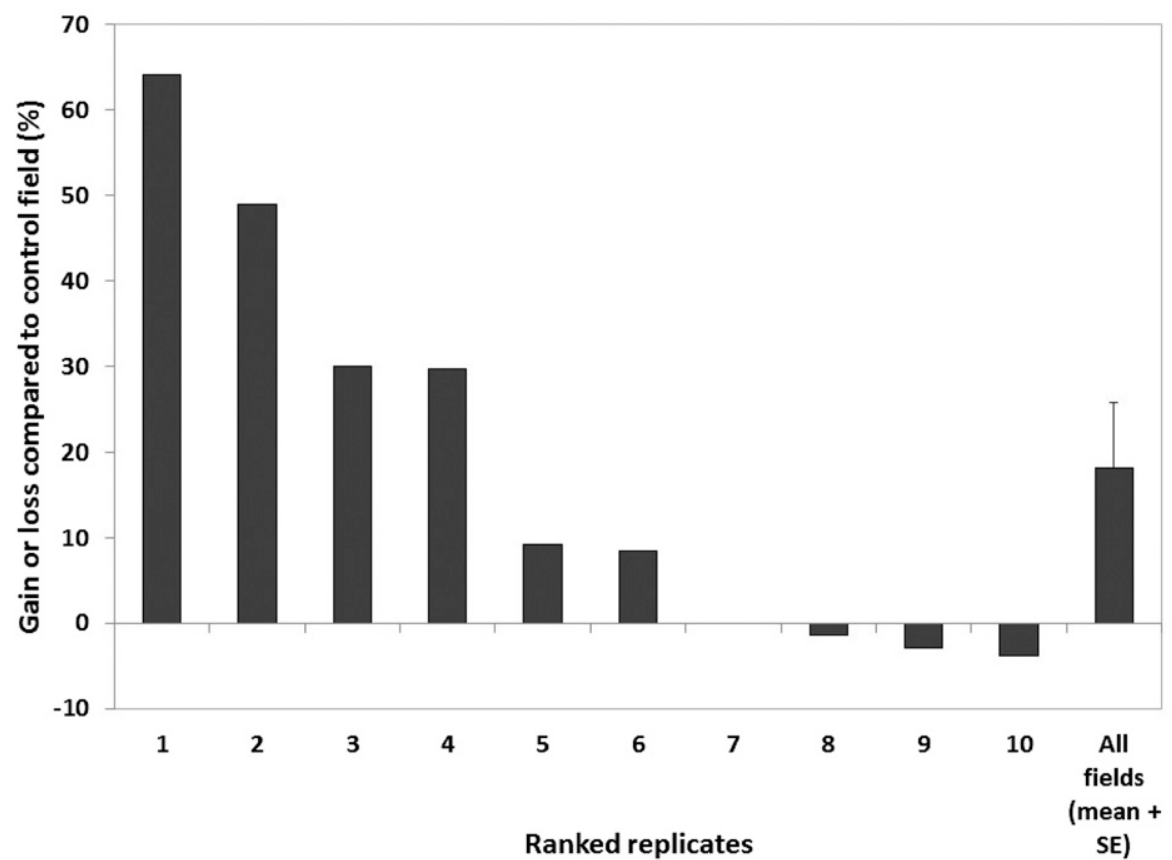

Fig. 3. Graph showing percentage increase or decrease in weight of harvested hybrid carrot seed in the brood pheromone field (honeybee colonies received brood pheromone) compared with control field (honeybee colonies did not receive brood pheromone) in each replicate. Bar at far right shows the mean percentage increase $(+\mathrm{SE})$ for all 10 replicates.

between pollen and nonpollen foragers, number and frequency of bees returning to the hive, or on the weight of pollen carried by returning foragers. The results from this study constitute the first evidence based on actual field observations and measurement of flower visitation in support of the hypothesis that brood pheromone can stimulate foraging in honeybees. 
Further, our results suggest that increased flower visitations by bees due to brood pheromone treatment may lead to increased yields in carrot seed crop.

King et al. (2013) suggest that flower visitation may be a poor proxy for pollination because they found that $40 \%$ of plant-visitors in their study were not effective pollinators. However, they also found that legitimate pollinators for a given species of flower were a good indicator of pollination success. Our results suggest that in hybrid carrot seed production, flower visitation by honeybees (a legitimatemanaged pollinator) is a good predictor of pollination success.

Increased foraging has also been demonstrated following applications of honeybee queen mandibular gland pheromone. When QMP was applied daily on glass slides in the hive, the number of pollen foragers increased as did the weight of pollen brought back to the hive (Higo et al., 1992). When QMP was applied as a spray to the crop during bloom, enhanced foraging was observed on pome fruits [Rosaceae (Currie et al., 1992b)], cranberry (Currie et al., 1992a; MacKenzie and Averill, 1992), and blueberry (Currie et al., 1992a).

The preference of honeybees for male flowers documented in this study suggests that there may be a greater reward to the bees in foraging on one sex of carrot flower than the other. In hybrid carrot seed, male flowers offer nectar and viable pollen, while female flowers offer nectar and some nonviable pollen or no pollen. The stronger preference for male flowers in treatment fields than control fields (Table 1) may be due to more intensive foraging by bees from pheromone-treated colonies once they had made an initial choice for male flowers. Alternatively, the bees may have been preferentially foraging on male flowers for quality (viable) pollen or high amounts of nectar. Our results support the findings of Erickson and Peterson (1979) that male-sterile lines in carrot were not able to attract significant number of honeybees when compared with male-fertile lines. Similar cases of flower discrimination occur in other flowering crop plants. In kiwifruit (Actinidia deliciosa), honeybees showed up to a 6-fold preference for female (pistillate) flowers, which have functional ovaries but nonviable pollen, over male (staminate) flowers, which have nonfunctional ovaries and viable pollen (Goodwin and Steven, 1993). In onion (Allium cepa), both honeybees and a native ground-nesting bee (Halictus farinosus), showed over a 3 -fold preference for male-fertile over male-sterile flowers (Parker, 1982).

Honeybees are known to exhibit constancy in species of flower on which they forage (Free, 1963), but it is not known whether constancy extends to sex of flower within a species. Because bees must move from male to female flowers to ensure hybrid carrot seed production, the extent of sex-specific constancy, or lack of it, would be an important determinant in the efficiency of honeybees used in carrot seed production. We did not categorize bees as pollen or nectar foragers while conducting flower visitation counts and hence cannot confirm if the bees were preferentially foraging for pollen or nectar.

COLONY FORAger COUNTS. Brood pheromone increased the total number of foragers and the proportion of pollen foragers in colonies that received synthetic brood pheromone. These results support the findings of few other previous brood pheromone studies where pollen foraging and overall foraging was documented to increase after application of brood pheromone to experimental colonies (Pankiw, 2004, 2007). Greater number of pollen foragers result from increased pollen foraging stimulus elicited by brood pheromone (Pankiw and Page 2001; Pankiw and Rubink 2002). Pollen gathering is vital for colony growth and maintenance, and hence we speculate that increased pollen foraging results in higher colony growth that in turn leads to greater number of foragers visiting the target crop.

YIELD. The significant increase in yield of seed carrot from fields where honeybee colonies were treated with brood pheromone (Fig. 2) supports the observation in watermelon (Guerra Sanz and Roldán Serrano, 2008) that brood pheromone can be used to increase crop yield. The data in Fig. 3 indicate that increases in yield cannot be expected in each instance that brood pheromone is used. Factors that may result in no positive effect in yield include optimal pollination conditions and extremely vigorous colonies that may negate any need for a supplementary foraging stimulus. For example, Currie et al. (1992a) achieved an improvement in yield of $\approx 40 \%$ in cranberry in 1989 when pollination conditions were poor, but found no increase in 1990 when pollination conditions were more favorable, even though more vigorous foraging was induced by the QMP treatment. If certain crops had greater yield potential than is commonly realized, higher yields might be achieved even under optimal pollination conditions. Brood pheromone might be especially beneficial when used in crops that do not offer optimal quantity and quality resources (nectar and pollen) and hence are less attractive to bees.

Further, as brood pheromone stimulates foraging in honeybee colonies, it is logical to expect some negative effects on colony health. Our study did not monitor colony growth or other health parameters, hence we are unable to provide insights on this aspect, but several previous studies (Lait et al., 2012; Moeri et al., 2011; Pankiw et al., 2011) have not shown any adverse effect of brood pheromone on colony health if used for 3 to 15 weeks. As with any other field experiment, despite our efforts to control as many variables as possible there could have been some other variables or factors beyond our control that might have affected the yields obtained in each of the experimental fields to a certain extent during different years.

Cost-BENEFIT ANALYSis of BROOD PHEROMONE TREATMENT. The analysis in Table 2 is based on central Oregon carrot seed production in 2012 of $345 \mathrm{lb} /$ acre yield over an area of 4200 acres, with a market price of $\$ 12.7 / \mathrm{lb}$. The cost of treating with brood pheromone is based on a pheromone unit price of $\$ 5.00$ plus a labor cost to the beekeeper of $\$ 1.00$ per treatment, which would most likely be passed on to the grower. The $\mathrm{kg} /$ ha gain in yield assumes that the mean gain of $18.3 \%$ over 10 replicates (Fig. 3) observed in this study would occur similarly over the 4200 acres of seed carrot grown in central Oregon in 2012. The break-even increase in yield needed to recover the cost of $\$ 44.40 /$ ha pertaining to brood pheromone application is very low, and the return on investment is so high that much less than an $18.3 \%$ gain in yield would justify investment in brood pheromone treatment. If 
Table 2. Economic analysis of the cost and benefit of using honeybee brood pheromone to improve the yield of hybrid carrot seed in central Oregon.

\begin{tabular}{lc}
\hline Evaluation criterion & Value $^{\mathrm{z}}$ \\
\hline $\begin{array}{l}\text { Cost }(7.4 \text { hives x } \$ 6.00, \text { including cost of brood } \\
\text { pheromone and labor) }\end{array}$ & $\$ 44.40 / \mathrm{ha}$ \\
$\begin{array}{l}\text { Gain [based on yield of } 386.7 \mathrm{~kg} \cdot \mathrm{ha}^{-1} \text { in central } \\
\quad \text { Oregon in } 2012, \text { raised by } 18.3 \%(\text { Fig. } 3)]\end{array}$ & $70.8 \mathrm{~kg} \cdot \mathrm{ha}^{-1}$ \\
$\begin{array}{l}\text { Gain in revenue }(\text { based on } 2012 \mathrm{market} \text { price for } \\
\text { hybrid carrot seed of } \$ 27.93 / \mathrm{kg})\end{array}$ & $\$ 1,977.44 / \mathrm{ha}$ \\
$\begin{array}{l}\text { Break-even point (increased yield in } \mathrm{kg} / \mathrm{ha} \text { needed } \\
\text { to equal cost of } \$ 44.40 / \mathrm{ha})\end{array}$ & $1.59 \mathrm{~kg} \cdot \mathrm{ha}^{-1}$ \\
Return on investment $(\mathrm{ROI})[($ gain - cost $) \div$ cost $]$ & \\
\hline
\end{tabular}

${ }^{2} \$ 1.00 / \mathrm{ha}=\$ 0.4047 /$ acre, $1 \mathrm{~kg} \cdot \mathrm{ha}^{-1}=0.8922 \mathrm{lb} /$ acre.

extrapolated over the entire 4200 acres of seed carrot grown in 2012, the gain in yield of $70.8 \mathrm{~kg} \cdot \mathrm{ha}^{-1}$ would be worth $\$ 3,361,655$ to central Oregon carrot seed growers.

Stimulation of increased foraging, as shown in this study, can also be a form of crop insurance, resulting in increased yield during poor pollination years, and possibly in most years. We suggest that brood pheromone treatment could be used to improve yields in other pollination dependent crops that are pollinated by honeybees. In conclusion, this study has demonstrated that brood pheromone has the potential to increase foraging in honeybee colonies and thus increase seed yield in carrot seed crop.

\section{Literature cited}

Borden, J.H., M. Campbell, W. Card, J.A. McLean, B. Foster, and R.R. Sagili. 2013. Can treatment with brood pheromone increase honey production? Amer. Bee J. 153:338-339.

Currie, R.W., M.L. Winston, and K.N. Slessor. 1992a. Effect of synthetic queen mandibular pheromone sprays on honey bee (Hymenoptera: Apidae) pollination of berry crops. J. Econ. Entomol. 85:1300-1306.

Currie, R.W., M.L. Winston, K.N. Slessor, and D.F. Mayer. 1992b. Effect of synthetic queen mandibular pheromone sprays on pollination of fruit crops by honey bees (Hymenoptera: Apidae). J. Econ. Entomol. 85:1293-1299.

Delaplane, K.S. and D.F. Mayer. 2000. Crop pollination by bees. CABI, New York. NY.

Ellis, A. and K. Delaplane. 2009. An evaluation of Fruit-Boost as an aid for honey bee pollination under conditions of competing bloom. J. Apic. Res. 48:15-18.

Erickson, E.H. and C.E. Peterson. 1979. Asynchrony of floral events and other differences in pollinator foraging stimuli between male fertile and male sterile carrot inbreds. J. Amer. Soc. Hort. Sci. 104:639-643.

Foster, B., N. Foster, W. Kaa, and J. McLean. 2011. Synthetic brood pheromone evaluation. N.Z. Beekeeper 19:17-18.

Free, J.B. 1963. The flower constancy of honeybees. J. Anim. Ecol. 32:119-131.

Goodwin, R.M. and D. Steven. 1993. Behaviour of honey bees visiting kiwifruit flowers. N. Z. J. Crop Hort. Sci. 21:17-24.

Guerra Sanz, J.M. and A. Roldán Serrano. 2008. Influence of honey bees brood pheromone on the production of triploid watermelon. Proc. IXth EUCARPIA Mtg. Genetics and Breeding of Cucurbitaceae, Avignon, France, 21-24 May 2008. p. 385-389.

Hart, J. and M. Butler. 2004. Nutrient management guide: Hybrid seed carrot. Oregon State Univ. Ext. Serv. Publ. EM 8879-E.

Higo, H.A., S.J. Colley, and M.L. Winston. 1992. Effects of honey bee (Apis mellifera L.) queen mandibular gland pheromone on foraging and brood rearing. Can. Entomol. 124:409-418.

Howlett, B.G. 2012. Hybrid carrot seed crop pollination by the fly Calliphora vicina (Diptera: Calliphoridae). J. Appl. Entomol. 136:421-430.

Huang, Z.-Y. and G.E. Robinson. 1992. Honeybee colony integration: Workerworker interactions mediate hormonally regulated plasticity in division of labor. Proc. Natl. Acad. Sci. USA 89:1172611729.

King, C., G. Ballantyne, and P.G. Willmer. 2013. Why flower visitation is a poor proxy for pollination: Measuring single-visit pollen deposition, with implications for pollination networks and conservation. Method Evol. Ecol. 4:811-818.

Lait, C.G., J.H. Borden, E. Kovacs, O.E. Moeri, M. Campbell, and C.M. Machial. 2012. Treatment with synthetic brood pheromone (SuperBoost) enhances honey production and improves overwintering survival of package honey bee (Hymenoptera: Apidae) colonies. J. Econ. Entomol. 105:304-312.

LeConte, Y., G. Arnold, J. Trouiller, and C. Masson. 1990. Identification of a brood pheromone in honeybees. Naturwissenschaften 77:334-336.

LeConte, Y., J.-M. Becard, G. Costagliola, G. de Vaublanc, M. El Maataoui, D. Crauser, E. Plettner, and K.N. Slessor. 2006. Larval salivary glands are a source of primer and releaser pheromone in honey bee (Apis mellifera L.). Naturwissenschaften 93:237-241.

MacKenzie, K.E. and A.L. Averill. 1992. A new honey bee attractant, the queen mandibular pheromone. Cranberries 56:13-14.

Mayer, D.F., R.L. Britt, and J.D. Lunden. 1989. Evaluation of Bee-Scent ${ }^{\circledR}$ as a honey bee attractant. Amer. Bee J. 129:41-42.

Moeri, O.E., C.G. Lait, E. Kovacs, J.H. Borden, and M. Campbell. 2011. SuperBoost: Synthetic brood pheromone for enhancing spring build-up of overwintered honey bee colonies. J. Apic. Res. 50:265-271.

Mohammedi, A., D. Crauser, A. Paris, and Y. LeConte. 1996. Effect of a brood pheromone on honeybee hypopharyngeal glands. Comptes rendus de l'Academie des sciences, Sciences de la vie 319:769-772.

Pankiw, T. 2004. Brood pheromone regulates foraging activity of honey bees (Hymenoptera: Apidae). J. Econ. Entomol. 97:748-751.

Pankiw, T. 2007. Brood pheromone modulation of pollen forager turnaround time in the honey bee (Apis mellifera L.). J. Insect Behav. 20:173-180.

Pankiw, T., A.L. Birmingham, J.P. Lafontaine, N. Avelino, and J.H. Borden. 2011. Stabilized synthetic brood pheromone delivered in a slow-release device enhances foraging and population size of honey bee, Apis mellifera, colonies. J. Apic. Res. 50:257-264.

Pankiw, T., J.P. Lafontaine, and N. Avelino. 2010. Stabilized brood pheromone for manipulating the behavior and physiology of honey bees. US Patent No. 7,727,517. U.S. Patent Trademark Office, Washington, DC.

Pankiw, T. and R.E. Page, Jr. 2001. Brood pheromone modulates honeybee (Apis mellifera L.) sucrose response thresholds. Behav. Ecol. Sociobiol. 49: 206-213. 


\section{Research Reports}

Pankiw, T., R. Roman, R.R. Sagili, and K. Zhu-Salzman. 2004. Pheromonemodulated behavioral suites influence colony growth in the honey bee (Apis mellifera). Naturwissenschaften 91:575-578.

Pankiw, T. and W.L. Rubink. 2002. Pollen foraging response to brood pheromone by Africanized and European honey bees (Apis mellifera L.). Ann. Entomol. Soc. Amer. 95:761-767.

Parker, F.D. 1982. Efficiency of bees in pollinating onion flowers. J. Kans. Entomol. Soc. 55:171-176.

Peters, L., K. Zhu-Salzman, and T. Pankiw. 2010. Effect of primer pheromones and pollen diet on the food producing glands of worker honey bees (Apis mellifera L.). J. Insect Physiol. 56:132-137.

Rao, S. and W.P. Stephen. 2009. Bumble bee pollinators in red clover seed production. Crop Sci. 49:2207-2214.

Roper, T.R., A.L. Averill, and D.L. Mahr. 1990. Does Bee-Scent ${ }^{\circledR}$ attract honey bees and enhance cranberry pollination? Cranberries 54:8-9.

Sagili, R.R. and C.R. Breece. 2012. Effects of brood pheromone (SuperBoost) on consumption of protein supplement and growth of honey bee (Hymenoptera: Apidae) colonies during fall in a northern temperate climate. J. Econ. Entomol. 105:1134-1138.
Sagili, R.R. and T. Pankiw. 2009. Effects of brood pheromone modulated brood rearing behaviors on honey bee (Apis mellifera L.) colony growth. J. Insect Behav. 22:339-349.

Schultheis, J.R., J.T. Ambrose, S.B. Bambara, and W.A. Mangum. 1994. Selective bee attractants did not improve cucumber and watermelon yield. HortScience 29:155-158.

Sivaram, V., K.V. Jayaramappa, A. Menon, and R.M. Ceballos. 2013. Use of bee-attractants in increasing crop productivity in niger (Guizotia abyssinica. L). Brazil Arch. Biol. Technol. 56:365-370. 